\title{
Screening immigrants for latent tuberculosis: Do we have the resources?
}

\author{
Jonathon Campbell HBSc, Fawziah Marra BSc PharmD, Victoria Cook MD, James Johnston MD MPH
}

Competing interests: None declared.

This article has been peer reviewed.

Correspondence to: James Johnston, james.johnston@ bccdc.ca

CMAJ 2014. DOI:10.1503 /cmaj.131025
$\mathrm{T}$ he recently released seventh edition of the Canadian tuberculosis standards was extensively revised to reflect new information on control of tuberculosis in low-incidence countries. ${ }^{1}$ The new edition comprehensively addresses screening for latent tuberculosis infection in migrant populations, in keeping with other recently published guidelines. ${ }^{2.3}$ Given that $67 \%$ of active tuberculosis cases in Canada in 2010 occurred in foreign-born people, these recommendations represent a needed shift from case-finding and management of active tuberculosis toward identifying those at risk for active disease and those most likely to benefit from treatment of latent tuberculosis infection. ${ }^{1}$ An emphasis on diagnosis and therapy of latent infection in foreign-born populations seems to be the rational "next step" toward eliminating tuberculosis in Canada. However, implementation of these recommendations will likely apply added pressure to an already strained health care infrastructure.

The new Canadian standards recommend targeted screening for latent tuberculosis infection in migrants from high-incidence countries (i.e., countries with incidence $\geq 30$ per 100000$)$. ${ }^{.}$ Specifically, all nonrefugee migrants 20 years of age or younger, refugees 50 years of age or younger, and migrants with comorbidities that increase the risk of active tuberculosis are to be targeted for screening, which may include inquiry about symptoms, chest radiography, tuberculin skin testing or interferon gamma release assay. ${ }^{1}$ These new recommendations expand targeted screening to include all migrants 15-20 years of age, and they provide specific details on which adult migrants are to be screened. As such, they go beyond screening guided by local epidemiol-

\footnotetext{
- KEY POINTS

- The seventh edition of the Canadian tuberculosis standards calls for a large increase in targeted screening for latent tuberculosis in Canada's foreign-born population.

- If these recommendations are followed, an estimated one-third of the foreign-born population will require screening, at substantial cost.

- An alternative approach would be to focus screening efforts on recent migrants with established risk factors for active tuberculosis.
}

ogy and resources.

In 2011, a total of 248748 new permanent residents arrived in Canada, including 185305 people from regions with a high incidence of active tuberculosis. ${ }^{4,5}$ Of those from high-incidence regions, we estimate that 54188 were nonrefugee migrants 20 years of age or younger and that 11259 were refugees 50 years of age or younger. ${ }^{4.5}$ Using these 2 criteria for screening for latent tuberculosis infection, an estimated 65447 or $26.3 \%$ of new permanent residents to Canada in 2011 would have required screening. (The numbers given here were calculated from Citizenship and Immigration Canada and World Health Organization data, with uniform age distributions assumed for each age group and refugee age distributions assumed to resemble the age distribution of other permanent residents.)

Certain comorbidities, such as diabetes mellitus, also increase the risk of active tuberculosis. ${ }^{1}$ The prevalence of diabetes among migrants is difficult to estimate, as it varies with age, sex, source country, immigration classification, income level and duration of residence in Canada, among other factors. ${ }^{6}$ However, diabetes prevalence is conservatively estimated at $6.5 \%$ among permanent residents aged 20 to 65 years. ${ }^{6}$ We estimate that this would lead to an additional 7432 people requiring screening for latent tuberculosis infection in the 2011 permanent resident cohort, resulting in 72879 people or $29.3 \%$ of this cohort being screened. Other conditions that increase the risk of active tuberculosis include HIV infection, endstage renal disease, use of tumour necrosis factor inhibitors, smoking and alcohol misuse. ${ }^{1}$

In total, targeted screening based on demographic factors and comorbidities could conceivably result in more than one-third of the permanent resident cohort qualifying for screening for latent tuberculosis infection. With consideration of all 6.8 million foreign-born residents of Canada, the implications of these recommendations are expansive. For instance, if these recommendations were appropriately applied to foreign-born residents with diabetes, we estimate that 395000 people would require screening for latent tuberculosis infection ${ }^{2}$ (assuming an age 
distribution for the foreign-born population with diabetes similar to that of Ontario ${ }^{6}$.

To our knowledge, the anticipated cost of screening all foreign-born residents of Canada has not been explicitly quantified. This lack of a cost estimate likely reflects our poor understanding of migrant demographic characteristics and health status after landing. In British Columbia, the cost of tuberculosis screening starts at $\$ 29.79$ for a tuberculin skin test alone, and the cost is $\$ 464.91$ for an uncomplicated course of therapy for latent infection, not to mention the added cost of interferon gamma release assays and treatment for therapeutic complications. ${ }^{7}$ Factoring in the cost of therapy and its complications, Oxlade and associates $^{8}$ calculated an overall mean cost of $\$ 496.21$ to screen and, if necessary, treat one recent migrant from a country with high incidence of tuberculosis (based on total screening and treatment costs for 1000 migrants). This would translate to over \$36 million for the 72879 permanent residents in 2011 (based on age and diabetes). Screening costs would likely be higher for longer-term residents, as they would be on average older, with more comorbidities, and hence a higher likelihood of adverse events from therapy. (In the preceding all costs are adjusted to current dollar values, based on $17.2 \%$ inflation since 2004 [Bank of Canada]).

The benefit of screening uptake is more difficult to estimate. The risk of active tuberculosis in foreign-born individuals with latent tuberculosis infection varies by age, landing date, duration in Canada, comorbidities, country of birth and chest radiography findings, among other factors. ${ }^{1.9} \mathrm{To}$ estimate the benefit of screening for latent tuberculosis infection, a program in the United States retrospectively applied similar screening criteria to all foreign-born patients with active tuberculosis over a two-year period..$^{10}$ The authors reported that $57 \%$ of foreign-born patients with active tuberculosis met the criteria for screening for latent infection before diagnosis of active disease and that $38 \%$ of cases were ultimately preventable. Assuming that the demographic characteristics of Canadian migrants are similar, we could expect the new screening recommendations to prevent a similar proportion of cases of active tuberculosis among foreign-born people.

Screening foreign-born populations will likely reduce the incidence of active tuberculosis in Canada, but implementation will require increased health care capacity. Screening protocols for recent migrants could be incorporated into Citizenship and Immigration Canada's established post-landing surveillance activities. At the moment, however, only $2 \%$ of migrants are monitored with post-landing surveillance, so a significant scale-up in capacity would be required. ${ }^{1}$ Meanwhile, screening the larger population of foreign-born residents in Canada would likely necessitate leveraging of a network of public health, primary care and specialty clinics.

The new Canadian standards for tuberculosis highlight the need for enhanced programs for screening and treatment of latent tuberculosis infection in foreign-born populations. Although they are more detailed and substantive than prior recommendations, no clear road map for implementation is provided. Proper implementation will require a large resource commitment from all levels of government and buy-in from community partners. A successful program will engage federal policymakers (i.e., Citizenship and Immigration Canada), provincial and territorial agencies, communitybased health care workers and culturally safe organizations in planning policy. An approach focused on recent migrants from countries with high incidence of tuberculosis who have established demographic or medical risk factors for active disease would be the appropriate first step toward broader implementation of these recommendations.

\section{References}

1. Canadian tuberculosis standards, 7th edition 2013. Ottawa (ON): Canadian Thoracic Society; 2013. Available: www.respiratory guidelines.ca/tb-standards-2013 (accessed 2013 July 3).

2. Greenaway C, Sandoe A, Vissandjee B, et al. Tuberculosis: evidence review for newly arriving immigrants and refugees. CMAJ 2011;183:E939-51.

3. Tuberculosis: clinical diagnosis and management of tuberculosis, and measures for its prevention and control. NICE Clinical Guideline 117. London (UK): National Institute for Health and Clinical Excellence. Available: www.nice.org.uk/nicemedia/live /13422/53642/53642.pdf (accessed 2013 July 3).

4. Facts and figures 2011 - immigration overview: permanent and temporary residents. Ottawa $(\mathrm{ON})$ : Citizenship and Immigration Canada; 2012. Available: www.cic.gc.ca/english/resources/statistics /facts2011/index.asp (accessed 2013 July 3).

5. WHO TB burden estimates, 2011. Geneva (Switzerland): World Health Organization; 2011. Available: www.who.int/tb/country /data/download/en/index.html (accessed 2013 July 3).

6. Creatore MI, Moineddin R, Booth G, et al. Age- and sex-related prevalence of diabetes mellitus among immigrants to Ontario, Canada. CMAJ 2010;182:781-9.

7. Marra F, Marra CA, Sadatsafavi M, et al. Cost-effectiveness of a new interferon-based blood assay, QuantiFERON-TB Gold, in screening tuberculosis contacts. Int J Tuberc Lung Dis 2008;12: 1414-24.

8. Oxlade O, Schwartzman K, Menzies D. Interferon-gamma release assays and TB screening in high-income countries: a costeffectiveness analysis. Int J Tuberc Lung Dis 2007;11:16-26.

9. Langlois-Klassen D, Wooldrage KM, Manfreda J, et al. Piecing the puzzle together: foreign-born tuberculosis in an immigrantreceiving country. Eur Respir J 2011;38:895-902.

10. Walter ND, Jasmer RM, Grinsdale J, et al. Reaching the limits of tuberculosis prevention among foreign-born individuals: a tuberculosis-control program perspective. Clin Infect Dis 2008; 46:103-6.

Affiliations: University of British Columbia (Campbell, Marra, Cook, Johnston); BC Centre for Disease Control (Cook, Johnston), Vancouver, BC

Contributors: Jonathon Campbell wrote the initial draft. Fawziah Marra was involved in conception, development and revision of the paper. Victoria Cook was involved in making revisions to the paper. James Johnston contributed to conception and development of the paper and to revising the initial and subsequent drafts. All four authors gave final approval before submission. 